\title{
Cultura de mercado: literatura e publicidade no pré-modernismo brasileiro
}

\author{
Maurício Silva \\ Universidade Nove de Julho (São Paulo, Brasil)
}

RESUMO: O PRESENTE ARTIGO ANALISA O CONTEXTO CULTURAL BRASILEIRO DURANTE A PASSAGEM DO SÉCULO XIX PARA O XX, A PARTIR DE UMA PERSPECTIVA DA LEITURA, ENFATIZANDO AS RELAÇÕES ENTRE A LITERATURA E A PUBLICIDADE NO CONTEXTO DO PRÉ-MODERNISMO LITERÁRIO BRASILEIRO.

ABSTRACT: THE PRESENT ARTICLE ANALYSES THE CULTURAL CONTEXT OF BRAZILIAN PRE-MODERNISM SINCE THE READING PERSPECTIVE, AND POINTS OUT TO THE RELATIONSHIP BETWEEN LITERATURE AND PUBLICITY ON THE CULTURAL CONTEXT OF BRAZILIAN PRE-MODERNIST LITERATURE.

PALAVRAS-CHAVE: PRÉ-MODERNISMO, LEITURA, PUBLICIDADE, LITERATURA, JORNALISMO. KEYWORDS: BRAZILIAN PRE-MODERNISM, READING, PUBLICITY, LITERATURE, JOURNALISM. 
história da leitura pré-modernista no Brasil é feita de capítulos ainda pouco estudados: a relação entre literatura e publicidade na virada do século XIX para o XX é, nesse sentido, um dos que costumam passar à margem dessa história, a despeito de ser ela um dos fatores que permitem delinear o arcabouço cultural do sistema literário vigente no período. Atuando de modo determinante no fortalecimento do hábito de leitura e na própria formação do leitor brasileiro, na prosperidade do complexo editorial moderno e no desenvolvimento de uma literatura pretensamente autônoma, a publicidade pode ser vista como fenômeno sociocultural que serve de argumento privilegiado à constituição do que se convencionou denominar República das Letras.

Neste sentido, a relação aqui aludida manifesta-se, principalmente, de duas maneiras no cenário cultural brasileiro: como recurso de divulgação de autores e obras de literatura, instituindo estratégias de legitimação e visibilidade social, portanto numa relação em que a publicidade coloca-se a serviço da literatura; e como o emprego da literatura com finalidades publicitárias, por meio do qual se produzem uma série de peças literárias - sobretudo, poemas - esteticamente canhestros e de eficácia duvidosa, numa relação em que a literatura coloca-se a serviço da publicidade.

Não se deve descartar, na apreciação desse assunto, cuja complexidade vai além dos esboços críticos que aqui pretendemos apresentar, um fenômeno imprescindível à compreensão da dinâmica publicitária do período: trata-se do impacto da tecnologia na vida social e cultural do Brasil, na medida em que tal impacto teria incidência direta nas práticas de leitura e, consequentemente, nas estratégias relacionadas à publicidade pré-modernista. Basta lembrar, dentro deste contexto, de efeitos como o reaquecimento do mercado editorial, a implementação de novos hábitos de leitura, uma maior divulgação da literatura aqui produzida, o aparecimento das primeiras edições populares ou a publicação de obra com grandes tiragens, consagrando os nossos primeiros best-sellers, como Afrânio Peixoto (A esfinge, 1908), Monteiro Lobato (Urupês, 1918) ou Benjamim Costallat (Mlle. Cinema, 1923), (BROCA, 1960 e SODRÉ, 1977).

Daí decorre também o fato de praticamente todo o complexo editorial brasileiro - considerado, de forma resumida, como o conjunto de agentes integrados na produção material do livro, indo das oficinas gráficas e das editoras às livrarias e aos distribuidores - se concentrar nos grandes centros 
urbanos, os quais acabavam desfrutando-o e, por outro lado, incentivando o desenvolvimento tecnológico do país (HALLEWELL, 1985).

\section{I}

Cooptados como detentores de um discurso portador de credibilidade, muitos dos escritores pré-modernistas vêem-se na contingência de colocarem sua pena a serviço da publicidade, mas, em compensação, desfrutam de benefícios profissionais e sociais que a publicidade lhes pode oferecer, já que, neste contexto, ela emerge como mais um fator de desempenho profissional e visibilidade social.

Essa afirmação tem ainda mais validade se pensarmos em um tipo específico de publicidade, justamente aquela de que os próprios autores lançavam mão para a divulgação de suas produções ficcionais e/ou intelectuais, a que podemos chamar de publicidade editorial (SILVA, 1999).

Objeto que passa a ser encarado efetivamente como um bem de consumo a partir da atuação pioneira de Monteiro Lobato, o livro começa a ser visto, na época, não apenas como um veículo de divulgação de idéias e de exposição estética, mas como um produto por meio do qual o escritor poderia tanto adquirir legitimidade social quanto prover seu próprio sustento. Evidentemente, há uma série de fatores que contribuíram para o alargamento da publicidade editorial no Brasil da passagem do século, como o aumento do consumo de livros per capita (resultante, por exemplo, do crescimento do índice de alfabetização no país) ou a concorrência entre editores/vendedores que se tornava mais acirrada com o passar dos anos. Mas, certamente, foi um outro tipo de concorrência, muito mais deletéria ao consumo de livros e, consequentemente, à leitura no país que incentivou, indiretamente, a prática da publicidade editorial: trata-se da concorrência entre o livro e os diversos meios de comunicação que rapidamente se desenvolveram no período.

Esse novo fenômeno, que viria alavancar as relações ainda pouco frequentes e nada profissionais entre os escritores e a universo publicitário, pode ser ilustrado com o crescimento significativo da imprensa, o que tornava o jornal uma verdadeira ameaça à produção livresca, a despeito do desenvolvimento que a indústria editorial conheceu na época. Mas não é apenas contra 
a imprensa como um todo - e, em particular, contra o jornal - que o livro se volta: a concorrência faz-se de forma mais contundente contra o cinema, um inimigo bem mais temível, porque novo, feérico, inusitado (ARAÚJO, 1976). As palavras sintomáticas que José Agudo expõe em uma de suas obras demonstra bem essa sensação de quanto a leitura acabava perdendo terreno quando confrontada com o espetáculo oferecido pelas fitas cinematográficas:

Hoje, que a instrucção já se pode ministrar através das projecções cinematographicas, a faculdade da visão suppre todas as outras faculdades de coordenação exigidas pela leitura. Todos querem vêr, vêr e mais vêr. A comprehensão do visto ficará a mercê da capacidade mental de cada espectador, porque a preguiça de lêr vai até o ponto de pouca gente perder cinco minutos com a leitura dos programmas... (AGUDO, 1914, p. 114)

Diante dessas disputas e concorrências, a publicidade editorial parece ter sido uma das saídas - ou, ao menos, uma das formas de contornar o problema - encontradas pelos autores e/ou editores de livros no país. A intenção era evidente: por meio de uma estratégia de divulgação maciça, tornar o livro tão atraente quanto qualquer outro meio de comunicação, seja ele o jornal, a revista ou o cinema. Neste sentido, não faltaram tentativas - mais ou menos originais - de expandir a divulgação do livro por meio da publicidade, já desde meados do século XIX.

Revistas e jornais começam a publicar propagandas de recentes lançamentos editoriais; resenhas começam a ser escritas com mais frequência; conferências e palestras (que, no final das contas, acabavam funcionando também como modo de divulgação do livro) espalham-se por todo o território nacional, principalmente nos primeiros anos do século XX; folhetos publicitários começam a ser produzidos pelos editores; expandem-se as possibilidades de aquisição do livro, seja por meio da facilitação do acesso ao produto, seja por meio da compra a prazo; e até tiragens são maquiadas, a fim de despertar a atenção do público leitor para determinada obra. A rigor, tudo isso acabava desempenhando, com maior ou menor grau de êxito e aceitação pública, um importante papel de divulgação publicitária, além de acirrar ainda mais a disputa entre o livro e os demais meios de comunicação.

Alguns autores empenhavam-se pessoalmente na divulgação de suas obras, e nesse capítulo de nossa história sociocultural merece destaque a figura de 
Aluísio Azevedo, que não era rigorosamente um autor pré-modernista, mas preparou o terreno para muitos que viriam posteriormente. Com efeito, a trajetória desse célebre romancista, marcada por momentos de glória e desilusão, cruza-se não poucas vezes com o caminho trilhado pela história da publicidade editorial brasileira, como sugere em seu estudo, Milton Marques Júnior:

...adotando atitudes modernas para a sua época, Aluísio instaura um novo modo de perceber o fato cultural-literário no país, quer transformando o jornal de assinaturas num jornal de venda avulsa, quer tratando o livro como mercadoria, cujo êxito comercial depende da propaganda que se faz (JÚNIOR, 1995, p. 226).

Não causa espécie, neste contexto, o fato de Aluísio Azevedo poder ser considerado um dos mais célebres casos de mistificação literária no país, cuja intenção era exatamente chamar a atenção para o recém-publicado $A$ mortatha de Alz̧ira (1894): disfarçado sob o pseudônimo de Victor Leal, publica o romance citado na Gazeta de Notícias (1891), precedendo-o de um exasperado libelo contra os autores naturalistas (cujo maior representante no Brasil era ele próprio); assim, Aluísio aproveita para fazer uma dupla publicidade de sua produção literária: do livro que estava sendo lançado, que angariava simpatias por se apresentar como obra anti-naturalista, e dos demais que já publicara, que eram alçados à condição de vítima e tornados objeto de curiosidade para aqueles que ainda não os conheciam (BROCA, 1993).

Mas esse não é o único episódio ligado direta ou indiretamente à publicidade editorial em que Aluísio Azevedo se envolveu. A trajetória de seu primeiro romance de relevo, O mulato (1881), também contém momentos curiosos e insólitos: antes mesmo da publicação do citado romance, Aluísio faz publicar nas páginas de $A$ Pacotilha cartas inventadas de imaginários leitores sobre o inexistente romance. Tais cartas - quase sempre elogiosas - apressaram a edição do livro e continuaram aparecendo mesmo depois da publicação do mesmo, o que acabou ocasionando um relativo sucesso de vendagem (MENEZES, 1958 e MONTELLO, 1975).

Talvez o episódio mais curioso ligado à publicidade azevedina seja aquele relatado por Coelho Neto, em torno do romance O homem (1887), e reproduzido por vários estudiosos do período. Em crônica publicada para $A$ Noite, conta o ilustre maranhense que, na época da publicação de $O$ bomem, Aluísio 
"poz-se em campo, para fazer a propaganda da obra": imprimiu duas mil etiquetas com o título do romance para espalhar pela cidade, enrolando algumas delas e metendo-as dentro de alguns pães que se achavam no balcão de certa confeitaria; um dos fregueses, ao comer o pão, acha indignado o papelucho, reclamando do fato, o que atrai a curiosidade de muitos transeuntes; aproveitando a oportunidade, Aluísio chega-se ao balcão e exclama, depois de um silogístico jogo de palavras em que comparava o pão real ao pão espiritual e o Homem contido no pão ao "homem" contido na hóstia: "saiba o amigo e saibam quantos aqui se acham que este Homem, que aqui está, é um dos typos mais perfeitos da creação: 300 páginas, edição Garnier, e apparecerá depois d'amanhan". Segundo Coelho Neto, aquele foi o assunto do dia na Rua do Ouvidor, e fôra tamanho o estardalhaço que "no dia da exposição do livro, foram vendidos ao balcão uns trezentos e tantos exemplares", fazendo a alegria do velho Garnier (NETO, 1922, p. 106).

Parece que Aluísio já sabia, em fins do século XIX, aquilo que muitos outros autores só descobririam mais tarde e que ainda nos dias de hoje possui validade: que a leitura de um livro se deve, em grande parte, à publicidade que dele se faz antes e depois de seu lançamento.

\section{II}

Ganhando impulso durante a passagem do século, principalmente, em razão da profusão das revistas mundanas e dos hebdomadários, a publicidade coopta escritores e intelectuais, trazendo para seu campo de atuação personalidades do meio artístico e tornando-se, com isso, elemento integrante do imaginário da época, até então pouco habituada com técnicas e procedimentos propagandísticos destinados à venda de produtos diversos (RAMOS, 1985 e SÜSSEKIND, 1987).

$\mathrm{Na}$ verdade, instala-se no país uma desbravadora ideologia publicitária, capaz de vender praticamente tudo, de roupas a remédios, de livros a maquinário, de chocolates a veículos. E, evidentemente, com a colaboração indispensável dos escritores, transformados, agora, em autênticos agentes publicitários.

Essa "literatura" com finalidades publicitárias, responsável, sobretudo, como sugerimos antes, pela produção de poemas-reclame, espalha-se pelas 
páginas dos periódicos e jornais da época, promovendo pela primeira vez uma substancial aliança entre literatura e propaganda no Brasil, fenômeno que está a merecer estudo mais alentado e cuidadoso.

A propaganda invade, assim, os limites até então invioláveis da arte, como que profanando, aos olhos dos mais conservadores e puristas, a aura sagrada da literatura. Intromete-se, direta ou indiretamente, em praticamente todos os gêneros literários, da poesia ao romance, do teatro à crônica, da novela ao conto. Nos romances e nos contos aparece, muitas vezes, de forma subliminar, entremeando-se ao enredo, como simples referência - ainda que não-intencional - a algum comerciante ou casa da moda; nas crônicas surge de forma mais explícita, sendo até mesmo assunto central de algumas delas, motivando comentários e pontos-de-vista dos cronistas; no teatro, não surpreende que, em meio à evolução dos diálogos, surja referências diretas a nomes ligados a algum tipo de comércio da cidade. Apenas a título de exemplo, é curioso o episódio que, em tom irônico, um autor anônimo narra nas páginas da revista Fon-Fon!, aliás um dos periódicos que, ao lado de Ariel, Kosmos, A Cigarra, O Malho e muitos outros, lançaram mão da "literatura" como meio de divulgação publicitária (OLIVEIRA, 1997; PADILHA, 2001 e DIMAS, 1983): ainda nos ensaios da peça Rio em fraldas de camisa, Paulo de Lima (um dos autores, ao lado de André Lobão) recebe a visita de seu alfaiate, que o viera cobrar, levando o autor, sem dinheiro, à seguinte idéia: convidou seu alfaiate para a estréia e, reservadamente, pediu ao primeiro ator, Tavares, que, na cena em que tivesse de falar, por força do texto, o nome de uma alfaiataria, substituísse o nome original do texto pelo da Alfaiataria Fim de Século de Almeida \& Filho. Pensava, assim, fazer uma surpresa ao seu alfaiate e, pela propaganda subliminar veiculada, ficar livre da dívida. Mais tarde, contudo, André Lobão - o outro autor da peça e vítima do mesmo problema - pede ao mesmo Tavares o obséquio de, naquela mesma cena, dizer o nome da Alfaiataria Art-Nouveau de Fagundes e Cia., por ser igualmente devedor desta outra casa comercial. No dia da estréia, com Lima e Lobão na platéia, acompanhados de seus respectivos alfaiates, o ator Tavares, após ter seu vestuário elogiado na peça e tendo sido questionado onde o adquirira, responde: "(no) alfaiate da moda Magalhães e Fialho, Alfaiataria Dois Amores, rua da Carioca, n ${ }^{\circ}$ 106". E o autor da crônica finaliza: "o ladrão do Tavares também devia ao seu alfaiate" (ANÔNIMO, 1907). 
Mas é na poesia que se percebe com maior frequência, durante o período estudado, a ocorrência do fenômeno assinalado, já que durante o PréModernismo um número verdadeiramente impressionante de artistas passa a utilizar seu estro poético como modo de divulgação publicitária, numa insólita intersecção entre a literatura e a propaganda. Assim, nomes como os de Olavo Bilac, Martins Fontes, Coelho Neto, Pedro Rabelo, Guimarães Passos e muitos outros esmeravam em construir de pequenas quadras a infalíveis sonetos propagandeando supostos benefícios de marcas como as dos Fósforos Brilhante, do Fotógrafo Leterre, da Vela Brasileira, da Alfaiataria Simonetti, do Café Andalusa, da Casa Lopes Fernandes, etc. (MENEZES, 1960). Em Ricardo Paranhos, por exemplo, o anúncio faz-se sob a máscara de um conselho amigo, título de um dos poemas de sua safra de peças humorísticas:

- Sei, dona Ofélia, que a senhora

anda doente.

Deve tratar-se convenientemente e sem demora.

Há um medicamento,

Grindélia, que se encontra aqui em qualquer farmácia,

cuja eficácia

garanto no tratamento

de asma e tosse,

que é o que a senhora diz que anda a sofrer.

Antes que um dêsses males se lhe aposse

do organismo fraco e torne-se fatal,

ouça, dona Ofélia,

o que lhe vou dizer:

tome Grindélia

de Oliveira Júnior, o remédio ideal,

extraordinário, que não falha, que não nega

e que é, por isso, o que mais hoje se procura

no caso de asma, tosse ou rouquidão.

Tome Grindélia e eu lhe garanto a cura

com a presteza (calha aqui a comparação!)

com que o diabo um ôlho esfrega!.

(PARANHOS, s.d., p. 117) 
Nenhum desses poetas, contudo, teria sido tão profissional, no seu contato com a publicidade, quanto Bastos Tigre, responsável, inclusive, pela organização de um pequeno escritório denominado Publicidade Bastos Tigre. Ficaram célebres, por exemplo, as oitavas em estilo camoniano que publicou no periódico D. Quixote, parodiando Os Lusíadas, para propagandear o xarope Bromil, as quais intitulou, sugestivamente, Bromilíadas e cuja primeira estrofe é a seguinte:

Os homens de pulmões martirizados

Que, de uma simples tosse renitente, Por contínuos acessos torturados

Passaram inda além da febre ardente;

Em perigos de vida atormentados,

Mais de quanto é capaz um pobre doente,

Entre vários remédios encontraram,

O BROMIL que eles tanto sublimaram.

(MENEZES, 1966)

Mas, se na poesia de Bastos Tigre - e de outros autores de renome - a publicidade encontra canal perfeito para veicular suas mensagens comerciais, é numa série infindável de poetas anônimos que ela vai-se apoiar para expandir, de modo desenfreado, as relações, a estas alturas, já bastante comuns entre literatura e propaganda.

Neste sentido, nossos periódicos da época são verdadeiramente pródigos na divulgação de uma série de poemas anônimos (quadras, sonetos, sextilhas, oitavas, décimas, etc.), responsáveis pela divulgação do Sabão Reuter, da Casa Adamo, do pó de arroz Lady, do chocolate Lacta, da cerveja Hanseatica, da Alfaiataria do Gallo, do Sabão Dentifrício, das lojas Damas Elegantes, dos cigarros Suruby, etc. As poesias tanto podiam ser, como dissemos, um soneto, em que a descrição justaposta de produtos dos mais diversos gêneros lembraria, não fosse sua função declaradamente pragmática, uma sugestão modernamente dadaísta, em seu aparente nonsense, como nesta peça financiada por Montalvo e Cia., propagandeando a casa Figner Irmãos:

Graphophones, phonographos, brinquedos,

Leques, arminhos, pentes e tambores, 
Fogareiros, navalhas, reflectores,

Tudo o que serve aos juvenis folguedos;

Espingardas, caixinhas de segredos,

Caçarolas, esquadros e vapores,

Pastas, pennas, papel, copiadores,

Couraçadas de estanho, com torpedos;

Quinquilharias, louças e ferragens,

Pincéis, correntes, colleções de leis,

Escusado é buscar noutras paragens...

Embora em toda a parte o procureis,

Somente vos darão (e com vantagens):

Figner Irmãos, S. Bento, 26;

(ANÔNIMO, 1905)

Quanto podiam ser uma quintilha parnasiana das mais tradicionais, a qual não dispensa todo um universo lírico em que se repetem as metáforas de extração metalista, a utilização de uma linguagem marcada pelo preciosismo vocabular e pelo purismo gramatical, o descritivismo verborrágico, muito próximo do retoricismo clássico, o emprego de vocábulos eruditos e raros, denotando o rebuscamento vocabular, tudo isso para falar... dos bombons Falchi:

Ouve, querida, a minha voz pathetica.

Do mundo alheio ás importunas criticas,

Amo-te, e tua juba longa e esthetica,

Quero affagal-a numa furna poetica,

Á sombra das pyramides graniticas.

Quero-te junto a mim, como crysalida

Entre os braços floridos de um arbusculo.

Repousaremos sobre a areia calida,

Vendo a noite surgir, tremula, palida,

Desfolhando os lilazes do crepusculo. 
Sobre um leito de folhas odoriferas,

Onde fulgem de orvalho argenteas perolas,

Sonharemos em noites estelliferas...

E acordaremos em manhãs magnificas,

Das fontes escutando as aguas querulas.

Percamos nosso instincto horrendo e vandalo.

Sejamos mais humanos, mais hygienicos.

Teu rude paladar com o Falchi abranda-lo,

Porque o Falchi é mais suave do que sandalo

$\mathrm{E}$ os pomos de ouro dos jardins edenicos!

(ANÔNIMO, 1918)

Com efeito, empregando metáforas de cunho classicizante, vazadas em pentásticos decassilábicos de sintaxe rebuscada e figuradas em hipérbatos construídos em forma parnasiana, o poema transcrito representa a mais perfeita conjunção entre uma forma esteticista e um conteúdo pragmático, segundo declarados propósitos mercadológicos e levando ao limite a inusitada relação entre a literatura e a publicidade.

\section{III}

A história da leitura pré-modernista no Brasil - como, de resto, a de todas as outras épocas e períodos - é feita de capítulos pouco aludidos e menos ainda estudados: capítulos que dizem respeito a fenômenos diversos, como procuramos ressaltar aqui, que vão da consideração do papel das editoras e livrarias no contexto cultural brasileiro a questões relativas a fatores ligados à publicidade.

Faz parte desse quadro, igualmente, o estudo não dos fenômenos, como vínhamos fazendo até agora, que funcionam como engrenagens de um complexo destinado a consolidar o processo de leitura no período, mas dos agentes que se situam virtualmente do outro lado desse mesmo processo: o leitor. Como semelhante abordagem requer um esforço e uma intenção que extrapolam os limites desse ensaio, acabamos por omitir deliberadamente essa 
outra perspectiva do problema. De qualquer maneira, tal consideração fica como sugestão para um trabalho futuro mais extenso e que procure desvendar este outro capítulo de nossa longa e inexplorada história, uma história feita, lobatianamente, de homens e livros.

\section{Referências bibliográficas}

ANÔNIMO. Alfaiates. Fon-Fon!, Rio de Janeiro, n. 27, out 1907.

ANÔNIMO. A Cigarra, São Paulo, n. 91, mai 1918.

ANÔNIMO. O Echo Phonographico, São Paulo, n. 36, fev 1905.

AGUDO, José. Cartas d'Oéste. São Paulo: O Pensamento, 1914.

ARAÚJO, Vicente de Paula. A bela época do cinema brasileiro. São Paulo: Perspectiva, 1976.

BROCA, Brito. A vida literária no Brasil. 1900. Rio de Janeiro: José Olympio, 1960.

BROCA, Brito. Teatro das letras. Campinas: Unicamp, 1993.

DIMAS, Antonio. Tempos eufóricos. Análise da Revista Kosmos: 1904-1909. São Paulo: Ática, 1983.

HALLEWELL, Laurence. O livro no Brasil: sua história. São Paulo: T.A. Queiroz, 1985. JÚNIOR, Milton Marques. Da Ilha de São Luis aos refolhos de Botafogo: a trajetória literária de Aluísio Azevedo da Província à Corte. Tese de Doutorado. Universidade Federal da Paraíba, João Pessoa, 1995.

MENEZES, Raimundo de. Aluísio Azevedo. Uma vida de romance. São Paulo: Martins, 1958.

MENEZES, Raimundo de. Emílio de Meneses. O último boêmio. São Paulo: Martins, 1960.

MENEZES, Raimundo de. Bastos Tigre e 'La Belle Époque”. São Paulo: Edart, 1966.

MONTELlo, Josué. Aluísio Azevedo e a polêmica d' 'O mulato'. Rio de Janeiro: José Olympio, 1975.

NETO, Coelho. Ainda uma vez... In: O men dia. Porto: Lello \& Irmão, 1922, p. 103-106.

OLIVEIRA, Ana Luiza Martins Camargo. Revistas em revista: práticas culturais em tempos de república, 1890-1922. Tese de Doutorado. Universidade de São Paulo, São Paulo, 1997.

PADILHA, Márcia. A cidade como espetáculo: publicidade e vida urbana na São Paulo dos anos 20. São Paulo: Annablume, 2001.

PARANHOS, Ricardo. Obras completas. Goiânia: Oficinas do Cerne, [s.d.].

RAMOS, Ricardo. Do reclame à comunicação. Pequena história da propaganda no Brasil. São Paulo: Atual, 1985. 
SILVA, Maurício. Profissionalização do escritor e publicidade editorial: dois capítulos da leitura pré-modernista no Brasil. Revista Magma, Universidade de São Paulo, São Paulo, n. 06, p. 65-77, 1999.

SODRÉ, Nelson Werneck. História da imprensa no Brasil. Rio de Janeiro: Graal, 1977. SÜSSEKIND, Flora. Cinematógrafo de Letras. Literatura, técnica e modernização no Brasil. São Paulo: Companhia das Letras, 1987.

Recebido em 03 de maio e aprovado em 29 de maio de 2011. 